\title{
MOCVD DEPOSITION OF ZINC AND BISMUTH CHALCOGENIDES FILMS ON THE SURFACE OF SILICA OPTICAL FIBRES
}

\author{
P. Kuznetsov a, G. Yakushcheva ${ }^{\text {a }}$, E. Savelyev ${ }^{\text {a }}$, V. Yapaskurt ${ }^{\text {a b }}$, V. Shcherbakov ${ }^{\text {a, b }}$, \\ A. Temiryasev ${ }^{\text {a }}$, L. Zakharov ${ }^{\text {a }}$, V. Jitov ${ }^{\text {a }}$, and D. Sudas ${ }^{\text {a,c }}$ \\ a Kotel'nikov Institute of Radio Engineering and Electronics (Fryazino Branch), Russian Academy of Sciences, \\ 1 Vvedenskogo sq., Fryazino, 14119 Moscow Region, Russia \\ ${ }^{\mathrm{b}}$ Department of Petrology, Geological Faculty, Moscow State University, Leninskie Gory, 119991 Moscow, Russia \\ ${ }^{c}$ Peter the Great St. Petersburg Polytechnic University, 195251 Saint Peterburg, Russia \\ Email: pik218@ire216.msk.su
}

Received 8 July 2019; accepted 14 October 2019

\begin{abstract}
Metal organic chemical vapour deposition (MOCVD) technology is adapted for the deposition of thin zinc and bismuth chalcogenides films on the surface of silica optical fibres with short tapered sections. Growth runs were carried out in a special tubular quartz reactor at atmospheric pressure of hydrogen at $425^{\circ} \mathrm{C}$ temperature using $\mathrm{ZnEt}_{2}$, $\mathrm{BiMe}_{3}, \mathrm{Et}_{2} \mathrm{Te}$ and i-Pro $\mathrm{Se}_{2}$ as organometallic precursors. During the deposition of chalcogenides, the transmittance spectra of the fibre were recorded in regular short time intervals. In the transmittance spectra of the fibre with a tapered section coated by ZnSe and ZnTe, lossy mode resonances (LMR) were observed at a diameter of the tapered waist below $30 \mu \mathrm{m}$. After the deposition of very thin $\mathrm{Bi}_{2} \mathrm{Te}_{3}$ and $\mathrm{Bi}_{2} \mathrm{Se}_{3}$ island films on the tapered waist with a diameter about $10 \mu \mathrm{m}$ optical fibres were built into erbium fibre ring lasers. A pulsed generation mode was achieved in some of lasers due to resonator Q-factor modulation. These results can be applied for the design of LMR fibre sensors and passively Q-switch pulsed fibre lasers.
\end{abstract}

Keywords: MOCVD, zinc and bismuth chalcogenides, tapered silica fibre, lossy mode resonance, Q-switch

\section{Introduction}

When transmitting optical radiation through optical fibres, it is important to isolate the light passing through the fibre core from the influence of the external environment. However, in some cases it is necessary to increase this interaction, in particular for sensory needs and the creation of laser elements based on saturable absorbers. One can solve this problem by creating a tapered part of the optical fibre and depositing thin films of semiconductor materials on its surface. Coating of the tapered fibre by a thin film of the material with a positive real part of the permittivity higher in magnitude than both the imaginary part of permittivity and the permittivity of the surrounding medium leads to the appearance of lossy modes propagating in the film along the waveguide. The number of lossy modes increases with increasing the film thickness. A coupling between a waveguide mode and a specific lossy mode of a thin film at a particular value of film thickness leads to attenuation dips in the transmission spectra (LMR) [1-3]. The coupling requires overlapping of mode fields and matching of mode phases, namely, equality of the real part of propagation constants of the lossy mode and the waveguide mode. Usually indium, tin and titanium oxides, 
their solid solutions and a number of polymers are used as coatings for LMR. This series of materials satisfies the conditions of LMR realization: they have the permittivity with sufficiently large real and insignificant, but not equal to zero, imaginary parts. However, their refractive index, a high value of which is one of the main factors for obtaining high sensitivity sensors based on LMR, does not exceed a value of 2.1 in a spectral range of 1.0$2.2 \mu \mathrm{m}$. To the best of our knowledge, such materials as ZnSe and ZnTe with higher values of the real part of permittivity, which even at a wavelength of $2.2 \mu \mathrm{m}$ are about 2.44 and 2.71 , respectively [何, have not been used for this purpose. Zinc selenide and zinc telluride crystallize in a sphalerite-type cubic lattice, the band gap of which at room temperature is 2.7 and $2.2 \mathrm{eV}$, respectively [5]. ZnSe has conductivity of an electronic type, and ZnTe has a hole-type conductivity. Due to the ability of in situ recording of the optical transmittance spectra during the deposition of semiconductor films by MOCVD on tapered silica fibres [6], it is possible to control the spectral position, shape, depth and width of the LMR line.

The saturation of optical absorption with increasing intensity of incident radiation in a wide spectral range, and a very fast relaxation, when removing the excitation discovered recently 81, is a unique property of thin films of topological insulators such as $\mathrm{Bi}_{2} \mathrm{Se}_{3}$ and $\mathrm{Bi}_{2} \mathrm{Te}_{3}$, which can be widely used in quantum optics and lasers. Narrow-band chalcogenides of bismuth $\mathrm{Bi}_{2} \mathrm{Se}_{3}$ $\left(0.3 \mathrm{eV}\right.$ ) [9] and $\mathrm{Bi}_{2} \mathrm{Te}_{3}$ (data varies from 0.13 to $0.21 \mathrm{eV}$ ) [10] have rhombohedral crystal lattices. In these semiconductors, the quintuple blocks of $\mathrm{Ch}-\mathrm{Bi}-\mathrm{Ch}-\mathrm{Bi}-\mathrm{Bi}$ (Ch is selenium or tellurium) are interconnected by weak van der Waals bonds. In most cases, the deposited $\mathrm{Bi}_{2} \mathrm{Se}_{3}$ films have an electronic type of conductivity, and $\mathrm{Bi}_{2} \mathrm{Te}_{3}$ has a hole-type conductivity.

To date, a large number of papers are devoted to $\mathrm{Bi}_{2} \mathrm{Se}_{3}$ and $\mathrm{Bi}_{2} \mathrm{Te}_{3}$ as saturable absorbers (SA) for creating pulsed fibre lasers. Such lasers can be divided into two types. The first type is lasers with passive mode locking, which are realized when it is necessary to obtain short-pulse ( $\tau<1 \mathrm{ps}$ ) radiation. The second type is the lasers operating on the basis of passive Q-switching, which give high energy pulses with long enough duration (in the range of several microseconds). To inte- grate SA materials into a fibre laser system several schemes are implemented. The simplest approach is to apply a thin film of SA on the face of the fibre [11], however, this results in a relatively low damage threshold. Another approach is to place the SA material on the surface of the partially polished fibre (the so-called D-shape fibre) [12-13]. In this case the damage threshold increases significantly, since only the evanescent field interacts with SA, and an increase of the interaction length results in a strong nonlinear response. But an asymmetric design of such a device causes unwanted polarization losses, which can be avoided by reducing the interaction length or using the tapered fibres [14]. According to the method of fabrication, the latter are divided into fused fibre tapers [15] and chemically etched fibre tapers [16].

In this paper, we used the MOCVD technique to precipitate zinc and bismuth chalcogenides on chemically etched fibre tapers. During the deposition of the coating, the transmittance spectra of the tapers were recorded in regular short time intervals. As a result, we managed to implement first LMRs using thin ZnSe and ZnTe films and to fabricate a pulsed ring erbium laser with passive Q-switching (Q-switch) using $\mathrm{Bi}_{2} \mathrm{Te}_{3}$ films.

\section{Materials and methods}

\subsection{Manufacturing of short fibre tapers}

The fabrication of a silica taper with a chalcogenide coating was conducted in several stages. First, the protecting polymer coating was uncovered on the section of a silica fibre SMF28 of a length of $2-10 \mathrm{~mm}$ and then the fibre was mounted on the board with a fluoroplastic covering. For fibre etching we used a non-toxic solution $\mathrm{NH}_{4} \mathrm{~F}+\left(\mathrm{NH}_{4}\right)_{2} \mathrm{SO}_{4}+\mathrm{H}_{2} \mathrm{O}$ [17]. The bare section of the fibre was immersed for $3 \mathrm{~h}$ in $1 \mathrm{ml}$ of the freshly prepared solution; the hydrophobic surface of the fluoroplastic did not allow the solution to extend. The selected molar ratios of $\mathrm{NH}_{4} \mathrm{~F}:\left(\mathrm{NH}_{4}\right)_{2} \mathrm{SO}_{4}: \mathrm{H}_{2} \mathrm{O}$ etchant at $22^{\circ} \mathrm{C}$ temperature provided an etching rate of $0.4 \mu \mathrm{m} / \mathrm{min}$ and after $3 \mathrm{~h}$ the fibre diameter decreased to about $50 \mu \mathrm{m}$. Then we removed the protective coating from $75 \mathrm{~mm}$ sections of the fibre on both sides of the taper. We immersed again a $20 \mathrm{~mm}$ part of the fibre with a taper in the centre into the etching solution 
and continued etching to the required diameter of the tapered waist $(10-40 \mu \mathrm{m})$. An optical image of the taper prepared for precipitating chalcogenides is presented in Fig. 1 .

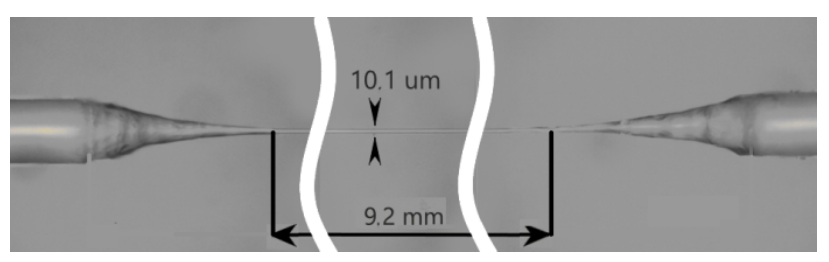

Fig. 1. An optical image of one taper before the deposition of chalcogenide.

\subsection{Deposition of chalcogenides}

For the deposition of zinc and bismuth chalcogenides on the surface of tapers, a special tubular quartz reactor heated by a resistance furnace was manufactured. A sketch of the reactor is shown in Fig. 2.

Trimethylbismuth $\left(\mathrm{BiMe}_{3}\right)$, diethylzinc $\left(\mathrm{ZnEt}_{2}\right)$, diethyltellurium $\left(\mathrm{Et}_{2} \mathrm{Te}\right)$ and diisopropylselenium (iPro ${ }_{2} \mathrm{Se}$ ) were used, respectively, as bismuth, zinc, tellurium and selenium organometallic sources, whose purity was certified by electronic grade. $\mathrm{BiMe}_{3}, \mathrm{ZnEt}_{2}, \mathrm{Et}_{2} \mathrm{Te}$ and $\mathrm{iPro}_{2} \mathrm{Se}$ bubblers were held at $-15,10,25$ and $27^{\circ} \mathrm{C}$, respectively. The total hydrogen flow was equal to 0.8 and $0.5 \mathrm{l} / \mathrm{min}$ during the deposition of zinc and bismuth chalcogenides films, respectively. The films of $\mathrm{ZnSe}, \mathrm{ZnTe}$, $\mathrm{Bi}_{2} \mathrm{Te}_{3}$ and $\mathrm{Bi}_{2} \mathrm{Se}_{3}$ were deposited at the same temperature of $425^{\circ} \mathrm{C}$. A relatively high temperature and a large excess of chalcogen during the depo- sition of bismuth chalcogenides by MOCVD (up to 40 in the case of $\mathrm{Bi}_{2} \mathrm{Se}_{3}$ ) are necessary in order to realize films with $\mathrm{Bi}_{2} \mathrm{Se}_{3}, \mathrm{Bi}_{2} \mathrm{Te}_{3}$ stoichiometry and to avoid the deposition of numerous phases of the homologous series $n \mathrm{Bi}_{2} \bullet m \mathrm{Bi}_{2} \mathrm{Se}_{3}$ and $n \mathrm{Bi}_{2} \cdot m \mathrm{Bi}_{2} \mathrm{Te}_{3}$, where $n$ and $m$ are integers [17, 18.

An installation of small-diameter tapers into the reactor and their sealing is a technically difficult task that we managed to solve. The outer pigtails of the fibre were connected to the transmittance spectrum recording circuit schematically shown in Fig. 2. During the film deposition, the transmittance spectra of the taper were recorded in a range of $1-1.65 \mu \mathrm{m}$ wavelength in regular time intervals using a NIRQUEST-512 spectrometer controlled by the OceanOpticsView software. In these experiments a halogen lamp served as a light source. The transmittance coefficient was determined normalizing the spectrum of transmitting light to that of an uncoated taper (prior to any film deposition).

\subsection{Methods of post-growth study of coatings}

To determine the stoichiometry of the deposited films, we used an energy dispersive X-ray spectrometer (EDX) X-MaxN, which was fitted with an electron microscope. Analysis was performed with the program INCA, Oxford Instruments. To standardize and optimize the profiles of the emission lines of characteristic radiation the following standards were used: crystals $\mathrm{ZnS}(\mathrm{Zn}-\mathrm{L} \alpha), \mathrm{Bi}_{2} \mathrm{Se}_{3}$ (Bi-M $\alpha$ and Se-L $\alpha$ ) and PbTe (Te-L $\alpha$ ). The measurement of the standards and the analysis of

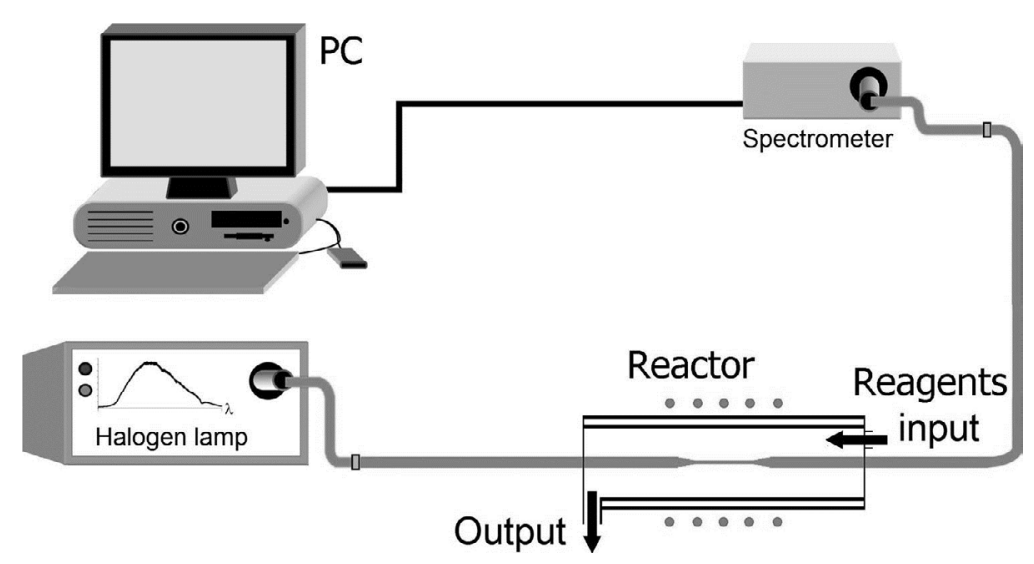

Fig. 2. A sketch of the reactor with in situ transmittance registration equipment used in this work for the deposition of zinc and bismuth chalcogenides on tapered fibres. 
the samples were performed under identical conditions at an accelerating voltage of $10 \mathrm{kV}$ and an electron probe current of $1.4 \mathrm{nA}$.

The surfaces of as-grown films were studied using a scanning electron microscope Jeol JSM6480LV with a tungsten thermionic cathode or on an atomic force microscope SmartSPM, AIST-NT7. Film thicknesses were defined by AFM microscopy using a scratch. Raman scattering spectroscopy was carried out at room temperature using a Micro-Raman spectrometer XPloRA (Horiba Scientific) excited with a solid state green laser $(\lambda=532 \mathrm{~nm})$ in the backscattering configuration. The signal was collected through a $100 \mathrm{x}$ objective lens and dispersed by the $1800 \mathrm{~g} / \mathrm{mm}$ grating under a triple subtractive mode with a spectra resolution of $\sim 1 \mathrm{~cm}^{-1}$. The lowest available frequency was $50 \mathrm{~cm}^{-1}$. The laser power and accumulation time of recording were varied from 0.3 to $3 \mathrm{~mW}$ and from 20 to $200 \mathrm{~s}$, respectively.

\section{Results}

\subsection{Lossy mode resonances at the deposition of $\mathrm{ZnSe}$ and $\mathrm{ZnTe}$ films on the tapered fibre}

We carried out series of experiments on the deposition of ZnTe and ZnSe films on the tapered fibres with different diameters from 10 to $40 \mu \mathrm{m}$. The curves in Fig. 3(a) show a change in the transmittance of the tapered fibre (the diameter of the taper $(d)$ is $15.5 \mu \mathrm{m}$ and the length $(l)$ $2.5 \mathrm{~mm}$ ) at two different wavelengths (1400 and $1565 \mathrm{~nm}$ ) versus the ZnSe film deposition duration. The change of the $\mathrm{ZnSe}$ film thickness during its deposition is also shown on the top of a horizontal scale.

The current film thickness was calculated by multiplying the average deposition rate by the precipitation process time. The deposition rate was determined using the final film thickness according to the AFM data and the duration of its deposition. Three resonance dips in the transmittance, which correspond to different orders of LMR, are clearly seen in both curves. The thicknesses of the $\mathrm{ZnSe}$ coatings at which resonance dips at a wavelength of $1400 \mathrm{~nm}$ occur are 35,85 , and $185 \mathrm{~nm}$, respectively. It is seen in Fig. 3(a) that in a certain range of the film thickness near LMRs of the first and second order, the transmit-
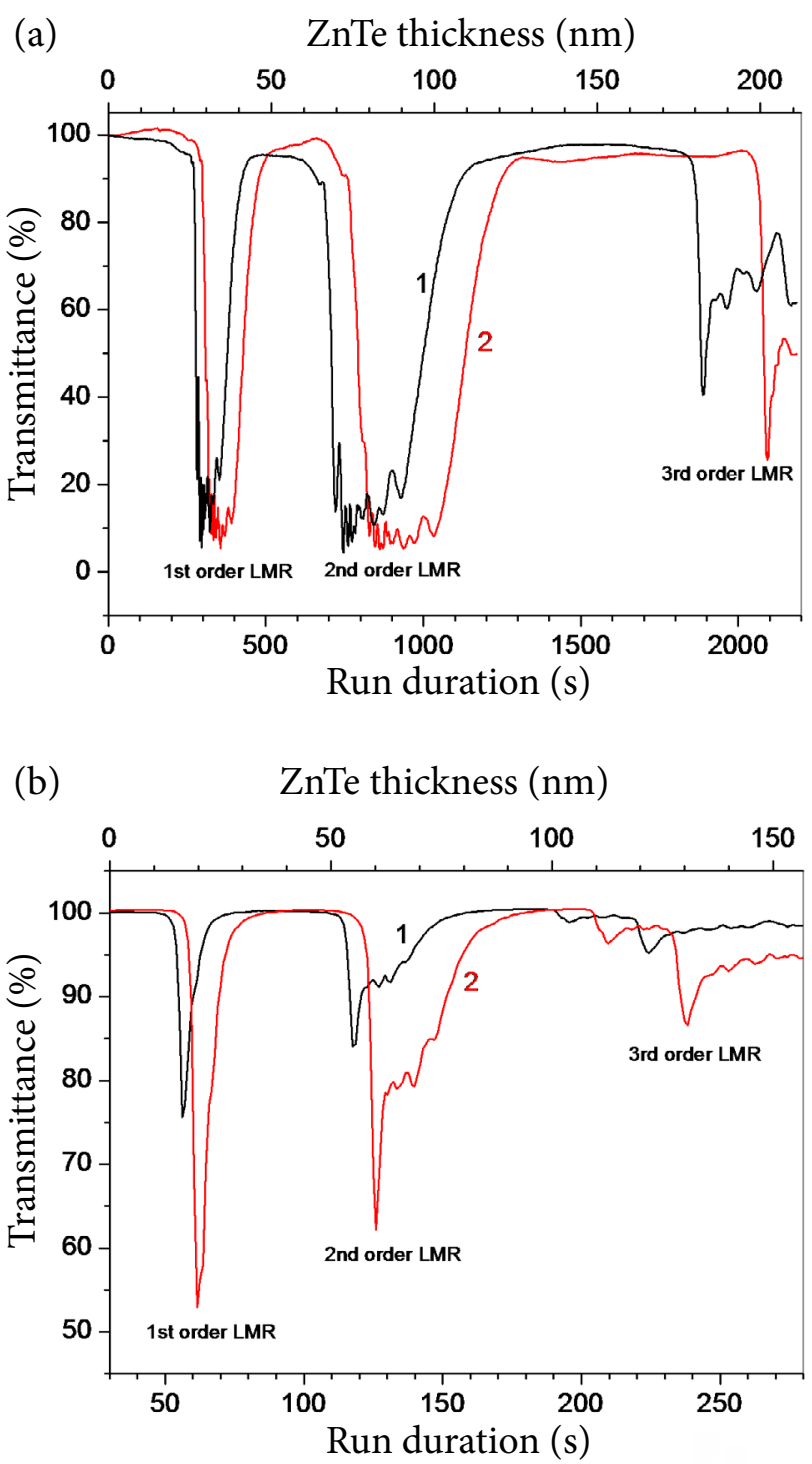

Fig. 3. Optical transmittance of tapered fibres versus the deposition duration of ZnSe and ZnTe films on their surfaces. Curves 1 and 2 correspond to wavelengths of 1400 and $1565 \mathrm{~nm}$. The taper parameters are $d=15.5 \mu \mathrm{m}, l=2.5 \mathrm{~mm}$ and $d=23.2 \mu \mathrm{m}$, $l=3.8 \mathrm{~mm}$ for (a) and (b), respectively.

tance is close to zero. This suggests that the diameter of the taper $(d=15.5 \mu \mathrm{m})$ is smaller than it is necessary to observe narrow resonances of these orders. Figure 3 (b) shows a change in the transmittance of the tapered fibre with $d=23.2 \mu \mathrm{m}$ and $l=3.8 \mathrm{~mm}$ with the ZnTe film deposition duration at two wavelengths. The transmittance at the deepest point of the first resonance dip is 0.75 and 0.5 for $1400 \mathrm{~nm}$ and $1565 \mathrm{~nm}$, respectively. Figure 4 shows the transformation of transmittance spectra for a short ZnTe film deposition duration when the first resonance is developing. 


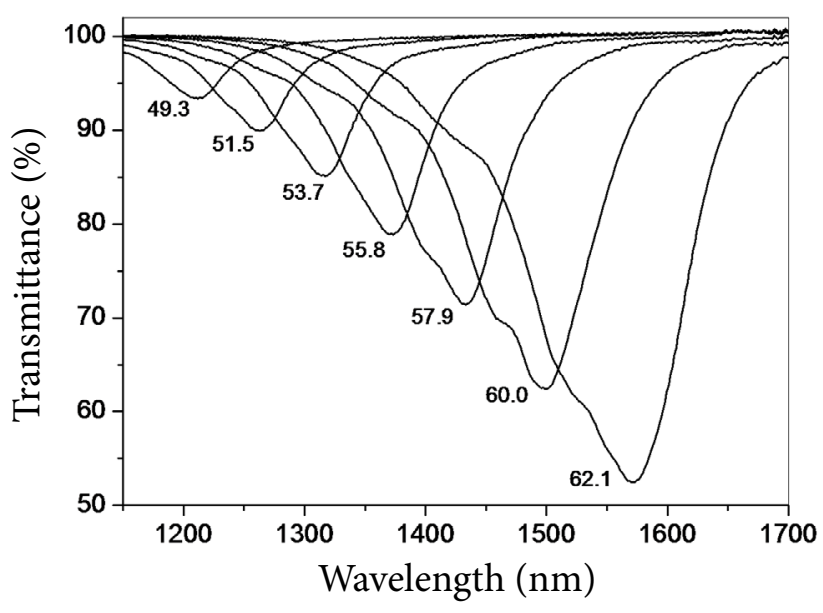

Fig. 4. Transmittance spectra transformation for a short ZnTe film deposition duration when the first resonance is developing. The tapered waist is $3.8 \mathrm{~mm}$ in length and the tapered waist diameter is $23.2 \mu \mathrm{m}$.

The minimum of the transmittance in the resonance dip decreases sharply from 0.93 to 0.53 with $13 \mathrm{~s}$ deposition time, and the minimum of the resonance dip shifts from 1210 to $1570 \mathrm{~nm}$. The width of the resonance dip increases from 65 to $136 \mathrm{~nm}$. According to the post-growth calculation, the film deposition rate equals $0.56 \mathrm{~nm} / \mathrm{s}$ and the increment of the coating thickness during this duration was only $7.2 \mathrm{~nm}$. The study of the optical transmittance spectra of a series of tapers with tapered sections of $5 \mathrm{~mm}$ in length and different diameters showed that a diameter of about $21 \mu \mathrm{m}$ provided a narrow resonance dip at a wavelength of $1565 \mathrm{~nm}$, corresponding to the first-order LMR, with transmittance not equal to zero.

Figure 5 shows the AFM images of square $2 \times 2 \mu \mathrm{m}^{2} \mathrm{ZnSe}$ and ZnTe film surfaces with a thickness of 80 and $260 \mathrm{~nm}$, respectively. In both images there are a lot of grains with a marked triangular shape. The roughness of the coatings is characterized by rms values of 2.9 and $10.6 \mathrm{~nm}$, respectively. These values are more than two orders of magnitude smaller than the wavelengths of the excited resonances and, in our opinion, the roughness does not affect the shape of resonances.

In the Raman spectrum of the $\mathrm{ZnSe}$ film there is a peak around $253 \mathrm{~cm}^{-1}$ due to the LO mode. In the Raman spectrum of the ZnTe film there is a peak around $200 \mathrm{~cm}^{-1}$ and three intense LOphonon replicas against the background of a wide PL emission. These spectra are not shown in this paper. The EDX spectra show that the examined

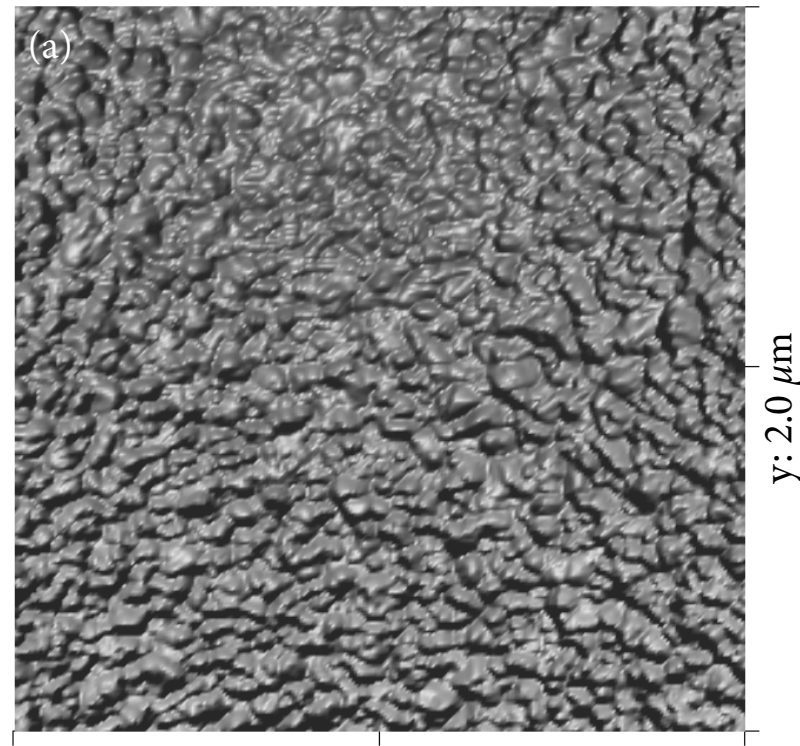

$\mathrm{x}: 2.0 \mu \mathrm{m}$

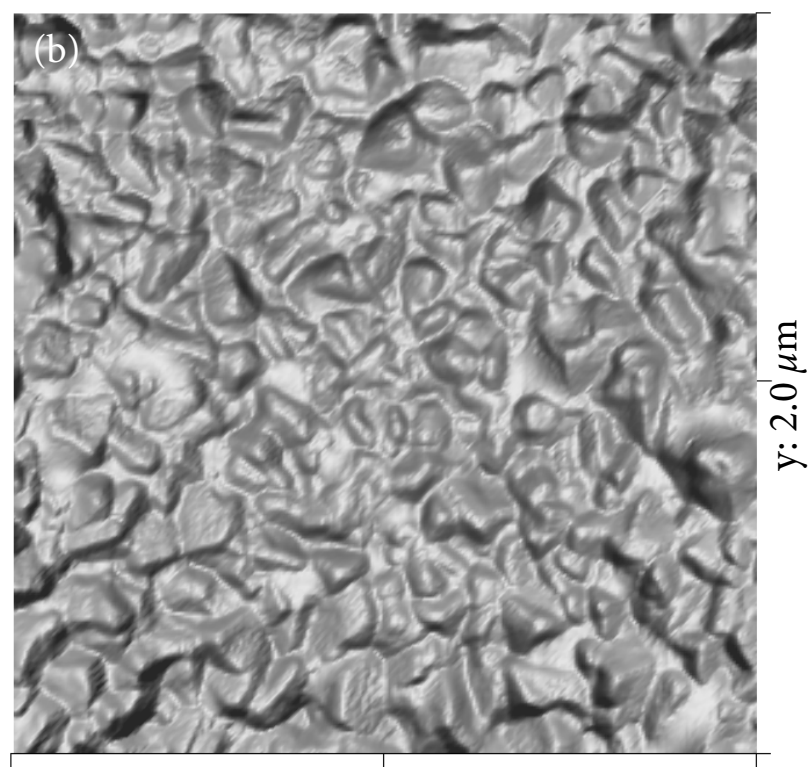

$\mathrm{x}: 2.0 \mu \mathrm{m}$

Fig. 5. AFM images of (a) the surface of the $\mathrm{ZnSe}$ film with a thickness of $80 \mathrm{~nm}$ and (b) the surface of the $\mathrm{ZnTe}$ film with a thickness of $240 \mathrm{~nm}$.

samples contain not only $\mathrm{Zn}$, Se or Te, but also $\mathrm{Si}$, $\mathrm{O}$ and sometimes Ge elements. The last three elements come from silica fibre.

The in situ transmittance spectra allowed us not only to control the deposition of $\mathrm{ZnSe}$ and $\mathrm{ZnTe}$ films on the tapered fibre, but also to find the temperature regimes of their complete decomposition by hydrogen, in order to reuse the same tapered fibre in our research. At $530^{\circ} \mathrm{C}$ temperature a sufficiently rapid removal of both $\mathrm{ZnSe}$ and $\mathrm{ZnTe}$ takes place. 


\subsection{Deposition of $\mathrm{Bi}_{2} \mathrm{Te}_{3}$ and $\mathrm{Bi}_{2} \mathrm{Se}_{3}$ films on the chemical tapered fibre}

During the deposition of $\mathrm{Bi}_{2} \mathrm{Se}_{3}$ and $\mathrm{Bi}_{2} \mathrm{Te}_{3}$ films, the quintuple block is bounded to the substrate by weak van der Waals bonds. Therefore, to form thin continuous films, it is necessary to neutralize the free bonds on the substrate surface. For this, a number of approaches are used; in particular, a two-stage process of low-temperature nucleation [19] and deposition of buffer layers of various selenides, including ZnSe [17] and ZnTe [18]. As we noted above in Section 2, the low temperature MOCVD deposition of $\mathrm{Bi}_{2} \mathrm{Se}_{3}$ and $\mathrm{Bi}_{2} \mathrm{Te}_{3}$ films leads to the formation of numerous phases with other stoichiometries. We did not deposit buffer layers of zinc chalcogenides to suppress the free bonds of the fibre surface, since their deposition leads to appearing of lossy modes and the manifestation of resonance phenomena. In addition, the island films can be used as SA in pulsed ring fibre lasers, which is one of the objectives of this study. As expected, the AFM investigation confirmed an island character of bismuth chalcogenide coatings deposited on the tapered fibre.

The EDX analysis of the composition of thick coatings confirmed the $\mathrm{Bi}_{2} \mathrm{Te}_{3}$ and $\mathrm{Bi}_{2} \mathrm{Se}_{3}$ stoichiometry of the deposited films. For thin island films, this stoichiometry was confirmed by Raman spectroscopy. The Raman spectra of the $\mathrm{Bi}_{2} \mathrm{Te}_{3}$ and $\mathrm{Bi}_{2} \mathrm{Se}_{3}$ islands showed peaks at wavenumbers of $58,99,132 \mathrm{~cm}^{-1}$ and $71,131,173 \mathrm{~cm}^{-1}$, respectively, which are slightly lower than those of active lattice vibrations $\mathrm{A}_{1 \mathrm{~g}}{ }_{\mathrm{g}}, \mathrm{E}_{\mathrm{g}}^{2}$ and $\mathrm{A}^{2}{ }_{\mathrm{r}}$, in a few quintuple $\mathrm{Bi}_{2} \mathrm{Te}_{3}$ and $\mathrm{Bi}_{2} \mathrm{Se}_{3}$ materials [20].

\subsubsection{In situ transmittance spectra at the deposition of $\mathrm{Bi}_{2} \mathrm{Se}_{3}$ and $\mathrm{Bi}_{2} \mathrm{Te}_{3}$ coating on the tapered fibre}

Two series of transmittance spectra recorded during the deposition of the $\mathrm{Bi}_{2} \mathrm{Se}_{3}$ coating on the tapered fibres with a waist length of $5.2 \mathrm{~mm}$ and diameters of 8.6 and $13.2 \mu \mathrm{m}$ are shown in Fig. $6(a-b)$, respectively. Since the concept of thickness is not applicable to noncontinuous films with islands, we used the duration of the deposition process as a parameter characterizing the volume of deposited material on the taper surface, the current value of which is indi- cated by numbers on the top right of the curves. Both growth processes were carried out at $425^{\circ} \mathrm{C}$ temperature and a $\mathrm{Se} / \mathrm{Bi}$ ratio in the vapour phase of 40. In the transmittance spectra of the fibre with a taper diameter of $8.6 \mu \mathrm{m}$ (Fig. 6(a)), one can see some chaotic beats, but the transmittance is almost constant in a range of $1170-1650 \mathrm{~nm}$. After $8 \mathrm{~s}$ of the deposition, when the transmittance was less than $10 \%$, the deposition process was stopped. The transmittance spectra of $\mathrm{Bi}_{2} \mathrm{Se}_{3}$ deposited on the taper with a diameter of $13.2 \mu \mathrm{m}$ have a different character (Fig. 6 (b)). In a range of 4-11 s the transmittance spectra show a monotonous decrease of transmittance with increasing wavelength, the rate of which increases with time. Starting from the 13th second of the deposition, the transmittance does not change, and as can be seen from Fig. 6(b), the spectra corresponding to the deposition times from 13 to $15 \mathrm{~s}$ completely coincide.

Figure $6(c, d)$ shows a series of transmittance spectra in the formation of $\mathrm{Bi}_{2} \mathrm{Te}_{3}$ coating on the tapered fibres with taper waist diameters of $10 \mu \mathrm{m}$ (c) and $13.2 \mu \mathrm{m}$ (d), with slightly different waist lengths, 4.7 and $5 \mathrm{~mm}$, respectively. In the taper with a diameter of $10 \mu \mathrm{m}$, the transmittance drops sharply to almost zero during the first $2 \mathrm{~s}$ of deposition. The drop in transmittance in the long-wavelength part of the spectrum takes place only on the curves lower than those shown in Fig. 6(c). According to AFM, this coating is not continuous, the average height of the islands is $2.8 \mathrm{~nm}$, and therefore the average rate of their deposition is $1.4 \mathrm{~nm} / \mathrm{s}$. When $\mathrm{Bi}_{2} \mathrm{Te}_{3}$ is deposited on the fibre taper with a diameter of $14.3 \mu \mathrm{m}$, an increase in the transmittance in the shortwavelength region of the spectrum is observed; however, unlike the deposition of $\mathrm{Bi}_{2} \mathrm{Se}_{3}$ films on a similar taper (Fig. 6(b)), at the final deposition stage the transmittance spectra did not coincide. The in situ control of the transmittance of tapers with $\mathrm{Bi}_{2} \mathrm{Te}_{3}$ and $\mathrm{Bi}_{2} \mathrm{Se}_{3}$ coatings at $425^{\circ} \mathrm{C}$ deposition temperature showed a steady increase in transmission in the entire spectral range when we stopped the supply of reagents. This is due to the decomposition of bismuth chalcogenides by hydrogen. If it is necessary to reuse the tapered fibre for research purposes, bismuth chalcogenides can be completely removed in hydrogen at $480^{\circ} \mathrm{C}$. 

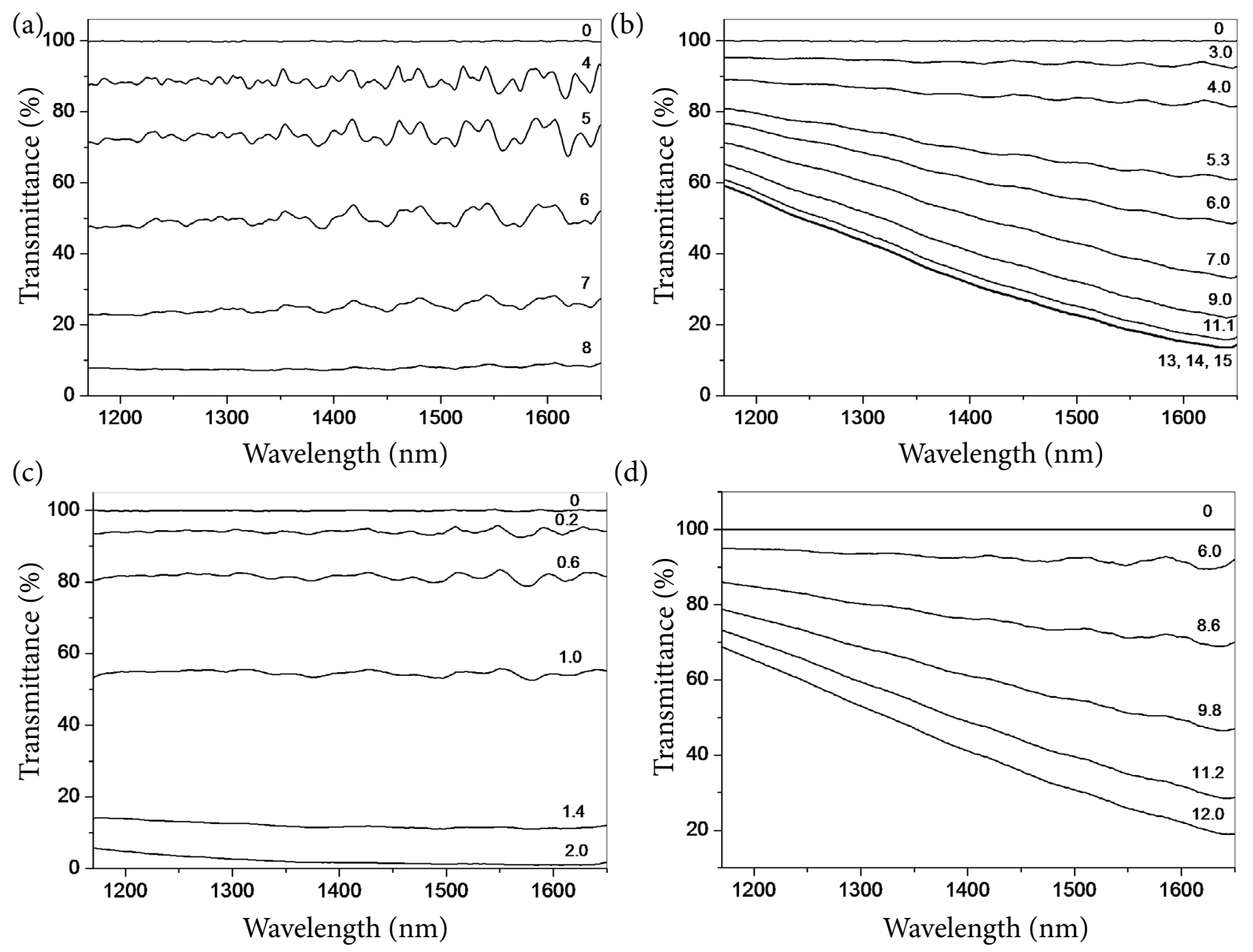

Fig. 6. Transmittance spectra during the deposition of $\mathrm{Bi}_{2} \mathrm{Se}_{3}(\mathrm{a}, \mathrm{b})$ and $\mathrm{Bi}_{2} \mathrm{Te}_{3}(\mathrm{c}, \mathrm{d})$ on the tapered fibre. Waist lengths and diameters of tapers are equal to: (a) $5.3 \mathrm{~mm}, 8.6 \mu \mathrm{m}$; (b) $5.2 \mathrm{~mm}, 13.2 \mu \mathrm{m}$; (c) $4.7 \mathrm{~mm}, 10.0 \mu \mathrm{m}$; (d) $5.0 \mathrm{~mm}, 14.3 \mu \mathrm{m}$. The numbers in the top of curves show the film deposition duration in seconds.

\subsubsection{Q-switched fibre lasers with $\mathrm{Bi}_{2} \mathrm{Te}_{3}$ coating as a saturable absorber}

Thin coatings of $\mathrm{Bi}_{2} \mathrm{Te}_{3}$ and $\mathrm{Bi}_{2} \mathrm{Se}_{3}$ were deposited on series of tapers with a diameter from 10.5 to $15 \mu \mathrm{m}$ to test as passive Q-switchers in a ring cavity of erbium fibre lasers. According to the AFM study, most of realized coatings are island films, on which bismuth chalcogenide islands occupy a small part of the taper surface. Figure 7 (a) shows an AFM image of the $\mathrm{Bi}_{2} \mathrm{Te}_{3}$ film on the taper with a waist length of $2.5 \mathrm{~mm}$ and a waist diameter of $14.8 \mu \mathrm{m}$ with $70.3 \%$ transmittance at a wavelength of $1.56 \mu \mathrm{m}$. Islands of an average height of $5 \mathrm{~nm}$ occupy no more than $20 \%$ of the surface of the taper. An increase in the density of the islands leads to a sharp decrease in transmittance. Thus, for the taper with a waist length of $3.0 \mathrm{~mm}$ and a diameter of $12.3 \mu \mathrm{m}$, and the surface, almost completely cov- ered by the islands with an average height of $11 \mathrm{~nm}$ (Fig. $7($ (b)), the transmission was only $2.3 \%$.

A set of the tapers with transmittance in a range of $70-90 \%$ at a wavelength of $1.56 \mu \mathrm{m}$ were built in the ring cavity of erbium fibre lasers and tested as passive Q-switchers. As a pump source of the lasers a fibre-coupled laser diode with a wavelength of $980 \mathrm{~nm}$ and an output power up to $300 \mathrm{~mW}$ was used. In the tested five tapers with the $\mathrm{Bi}_{2} \mathrm{Se}_{3}$ coating Q-swiching was not observed. The laser pulse generation was observed only on one taper with a waist diameter of $10.5 \mu \mathrm{m}$ and a length of $4 \mathrm{~mm}$ covered by a very thin $\mathrm{Bi}_{2} \mathrm{Te}_{3}$ coating. The taper transmittance was about $78 \%$ at a wavelength of $1.56 \mu \mathrm{m}$. This laser starts to operate in the CW mode at a pump power of $30 \mathrm{~mW}$. At pump powers from 34 to $40 \mathrm{~mW}$, pulses with a $\mathrm{kHz}$ repetition rate appear (see Fig. 7 , upper), which manifest the effect of the deposited SA layer. 
(a)

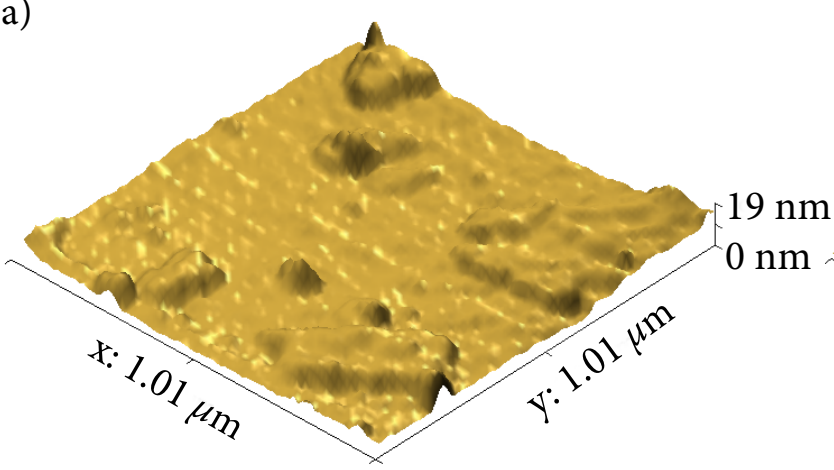

(b)

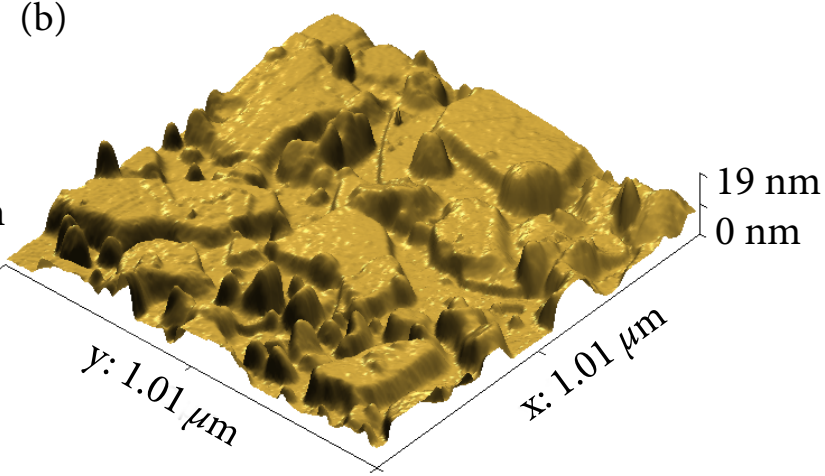

Fig. 7. AFM images of $\mathrm{Bi}_{2} \mathrm{Se}_{3}(\mathrm{a})$ and $\mathrm{Bi}_{2} \mathrm{Te}_{3}(\mathrm{~b})$ surfaces on the tapered waist of the fibre. Waist diameters of tapers are equal to (a) $8.6 \mu \mathrm{m}$ and (b) $12.3 \mu \mathrm{m}$.

The Q-switching in lasers with the thicker tapers arose after pouring the tapers with $\mathrm{Bi}_{2} \mathrm{Te}_{3}$ films by polymer coating (polydimethylsiloxane elastomer, the refractive index of which is 1.40 at $20^{\circ} \mathrm{C}$ temperature). For example, for the taper with a waist diameter of $13.0 \mu \mathrm{m}$ and $l=4 \mathrm{~mm}$, the transmittance fell from 90 to $48 \%$ after pouring the polymer. The laser started to operate in the $\mathrm{CW}$ mode at a pump power of $40 \mathrm{~mW}$ and the Q-switching was realised at pump powers of 48 to $107 \mathrm{~mW}$. The pulse train at $100 \mathrm{~mW}$ pump power is shown in Fig. 8 (bottom curve). The emergence of Q-switching can be explained by an in- crease of the energy density of the evanescent field of the laser radiation passing through the core of the fibre, and, as a consequence, the strengthening of its interaction with the SA film.

\section{Conclusions}

We have deposited zinc and bismuth chalcogenides on the tapered section of the silica fibre by MOCVD for the first time. For fabrication of the fibre tapers chemical wet etching based on a nontoxic solution of $\mathrm{NH}_{4} \mathrm{~F}+\left(\mathrm{NH}_{4}\right)_{2} \mathrm{SO}_{4}+\mathrm{H}_{2} \mathrm{O}$ was applied. The film deposition on the tapered

(a) Pump $=34 \mathrm{~mW}$ Pulse duration $=23.8 \mu$ sepetition rate $=14.0 \mathrm{kHz}$
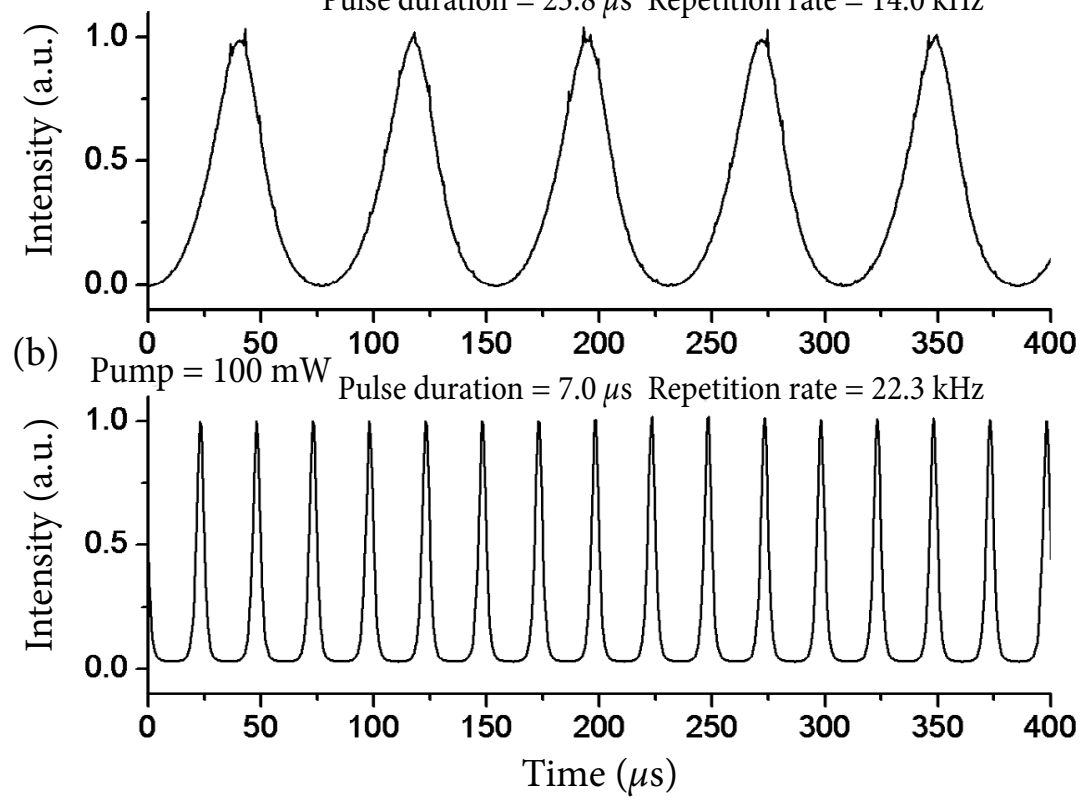

Fig. 8. The pulse train of the tapered fibre: with $\mathrm{Bi}_{2} \mathrm{Te}_{3}$ coating (upper) and double $\mathrm{Bi}_{2} \mathrm{Te}_{3}$. polydimethylsiloxane elastomer coating (below). The parameters of tapers are given in the text. 
fibres was carried out in a special tubular quartz reactor with registration of the transmittance spectra in real time.

The experimental results show that in the transmittance spectra of the fibre tapers of a diameter lower than $30 \mu \mathrm{m}$, covered by thin $(30-200 \mathrm{~nm})$ $\mathrm{ZnSe}$ and $\mathrm{ZnTe}$ films with high refractive indexes, narrow dips associated with the LMR phenomenon appear under certain conditions.

Ultrathin bismuth chalcogenide layers with a transmittance of $70-90 \%$ at a wavelength of $1.56 \mu \mathrm{m}$ were deposited on the tapered fibres of diameters from 10.5 to $15 \mu \mathrm{m}$. The $\mathrm{Bi}_{2} \mathrm{Se}_{3}$ and $\mathrm{Bi}_{2} \mathrm{Te}_{3}$ stoichiometry of the coatings deposited at $425^{\circ} \mathrm{C}$ is confirmed by EDX and Raman spectroscopy. The fibre tapers with deposited bismuth chalcogenide films were tested as SA in the erbium fibre ring laser. Pulse generation was obtained using a fibre taper with a diameter of $10.5 \mathrm{~nm}$ covered by an island $\mathrm{Bi}_{2} \mathrm{Te}_{3}$ coating. However, a narrow range of the power of pump laser radiation, for which this generation was observed, points out that the diameter of the taper has to be further reduced. It was found that a polymer coating on top of the deposited films makes it possible to realize Q-switchers on the tapered fibre up to $15 \mu \mathrm{m}$ in diameter. It is of interest to examine the possibility of using two-layer $\mathrm{Bi}_{2} \mathrm{Te}_{3}-\mathrm{ZnTe}$ and $\mathrm{Bi}_{2} \mathrm{Te}_{3}-\mathrm{ZnSe}$ heterostructures as SA. The MOCVD method allows us to deposit these heterostructures in a single technological cycle.

\section{Acknowledgements}

The work was carried out within the framework of the State Task and was partially supported by the Russian Foundation for Basic Research, Projects No. 17-07-00241A, 18-29-20101 MK, and the Ministry of Education and Science of Russian Federation (Grants No. 16.3788.2017/4.6 and 16.4959.2017/6.7). The authors would like to thank Dr. B. Shchamkhalova for fruitful discussions.

\section{References}

[1] I.D. Villar, F.J. Arregui, C.R. Zamarreño, J.M. Corres, C. Bariain, J. Goicoechea, C. Elosua, M. Hernaez, P.J. Rivero, A.B. Soccoro, et al., Optical sensors based on lossy-mode resonances, Sens. Actuators B 240, 174-185 (2017).
[2] N. Paliwal and J. John, Lossy mode resonance (LMR) based fiber optic sensors: A review, IEEE Sens. J. 15(10), 5361-5371 (2015).

[3] Q. Wang and W.-M. Zhao, A comprehensive review of lossy mode resonance-based fiber optic sensors, Opt. Lasers Eng. 100, 47-60 (2018).

[4] D.T.F. Marple, Refractive index of $\mathrm{ZnSe}, \mathrm{ZnTe}$, and CdTe, J. Appl. Phys. 35(3), 539-542 (1964).

[5] N.Kh. Abrikosov, V.F. Bankina, L.V. Poretskaya, L.E. Shelimova, and E.V. Skudnova, Semiconducting II-VI Compounds (Springer Science+ Business Media, New York, 1969) p. 26.

[6] P.I. Kuznetsov, V.A. Jitov, E.I.Golant, E.A.Savelyev, D.P. Sudas, G.G. Yakushcheva, and K.M. Golant, Transmission spectrum alteration of a silica fiber taper while covering lateral surface with heterostructure of $\mathrm{ZnTe} / \mathrm{Bi}_{2} \mathrm{Te}_{3}$ thin film, Phys. Scr. 94, 025802 (2019).

[7] C. Zhao, Y. Zou, Y. Chen, Z. Wang, S. Lu, H. Zhang, S. Wen, and D. Tang, Wavelengthtunable picosecond soliton fiber laser with topological insulator: $\mathrm{Bi}_{2} \mathrm{Se}_{3}$ as a mode locker, Opt. Express 20(25), 27888-27895 (2012).

[8] J. Lee, J. Koo, Y.M. Jhon, and J.H. Lee, A femtosecond pulse erbium fiber laser incorporating a saturable absorber based on bulk-structured $\mathrm{Bi}_{2} \mathrm{Te}_{3}$ topological insulator, Opt. Express 22(5), 6165-6173 (2014).

[9] J.G. Checkelsky, Y.S. Hor, R.J. Cava, and N.P. Ong, Bulk band gap and surface state conduction observed in voltage-tuned crystals of the topological insulator $\mathrm{Bi}_{2} \mathrm{Se}_{3}$, PRL 106, 196801 (2011).

[10]E.H. Kaddouri, T. Maurice, X. Gratens, S. Charar, S. Benet, A. Mefleh, J.C. Tedenac, and B. Liautard, Optical properties of bismuth telluride thin films, $\mathrm{Bi}_{2} \mathrm{Te}_{3} / \mathrm{Si}(100)$ and $\mathrm{Bi}_{2} \mathrm{Te}_{3} / \mathrm{SiO}_{2} / \mathrm{Si}(100)$, Phys. Status Solidi A 176, 1071-1076 (1999).

[11]Y.-H. Lin, C.-Y. Yang, S.-F. Lin, W.-H. Tseng, Q. Bao, C.I. Wu, and G.-R. Lin, Soliton compression of the erbium-doped fiber laser weakly started mode-locking by nanoscale $p$-type $\mathrm{Bi}_{2} \mathrm{Te}_{3}$ topological insulator particles, Laser Phys. Lett. 11, 055107 (2014).

[12]J. Boguslawski, G. Sobon, R. Zybala, and J. Sotor, Dissipative soliton generation in Er-doped fiber laser mode-locked by $\mathrm{Sb}_{2} \mathrm{Te}_{3}$ topological insulator, Opt. Lett. 40(12), 2786-2789 (2015). 
[13]J. Koo, J. Lee, C. Chi, and J.H. Lee, Passively Q-switched $1.56 \mu \mathrm{m}$ all-fiberized laser based on evanescent field interaction with bulk-structured bismuth telluride topological insulator, J. Opt. Soc. Am. B 31(9), 2157-2162 (2014).

[14]J. Bogusławski, G. Soboń, R. Zybała, K. Mars, A. Mikuła, K.M. Abramski, and J. Sotor, Investigation on pulse shaping in fiber laser hybrid mode-locked by $\mathrm{Sb}_{2} \mathrm{Te}_{3}$ saturable absorber, Opt. Express 23(22), 29014 (2015).

[15]P. Yan, R. Lin, S. Ruan, A. Liu, H. Chen, Y. Zheng, S. Chen, C. Guo, and J. Hu, A practical topological insulator saturable absorber for mode-locked fiber laser, Sci. Rep. 5, 8690 (2015).

[16]S. Ko, J. Lee, J. Koo, B.S. Joo, M. Gu, and J.H. Lee, Chemical wet etching of an optical fiber using a hydrogen fluoride-free solution for a saturable absorber based on the evanescent field interaction, J. Lightwave Technol. 34(16), 3766-3784 (2016).

[17]S.H. Ko, J.S. Lee, J.H. Koo, B.S. Joo, M.S. Gu, and J.H. Lee, Chemical wet etching of an optical fiber using a hydrogen fluoride-free solution for a saturable absorber based on the evanescent field interaction, J. Lightwave Technol. 34(16), 3776 (2016).

[18]P.I. Kuznetsov, V.A. Luzanov, G.G. Yakusheva, A.G. Temiryazev, B.S. Shchamkhalova, V.A. Zhitov, and L.Yu. Zakharov, Deposition of heteroepitaxial layers of topological insulator $\mathrm{Bi}_{2} \mathrm{Se}_{3}$ in the trimethylbismuth-isopropylselenide-hydrogen system on the (0001) $\mathrm{Al}_{2} \mathrm{O}_{3}$ and (100) GaAs substrates, J. Commun. Technol. El. 61(2), 183189 (2016).

[19]P.I. Kuznetsov, V.O. Yapaskurt, B.S. Shchamkhalova, V.D. Shcherbakov, G.G. Yakushcheva, V.A. Luzanov, and V.A. Jitov, Growth of $\mathrm{Bi}_{2} \mathrm{Te}_{3}$ films and other phases of $\mathrm{Bi}-\mathrm{Te}$ system by MOVPE, J. Cryst. Growth 455, 122-128 (2016).

[20]Z.Y. Wang, H.D. Li, X. Guo, W.K. Ho, and M.H. Xie, Growth characteristics of topological insulator $\mathrm{Bi}_{2} \mathrm{Se}_{3}$ films on different substrates, J. Cryst. Growth 334, 96-102 (2011).

[21]K.M.F. Shahil, M.Z. Hossain, V. Goyal, and A.A. Balandin, Micro-Raman spectroscopy of mechanically exfoliated few-quintuple layers of $\mathrm{Bi}_{2} \mathrm{Te}_{3}, \mathrm{Bi}_{2} \mathrm{Se}_{3}$ and $\mathrm{Sb}_{2} \mathrm{Te}_{3}$ materials, J. Appl. Phys. 111, 054305 (2012).

\title{
$\mathrm{SiO}_{2}$ ŠVIESOLAIDŽIŲ DENGIMAS CINKO IR BISMUTO CHALKOGENIDŲ PLĖVELĖMIS, AUGINTOMIS METALORGANINIO CHEMINIO GARŲ NUSODINIMO BŪDU
}

\author{
P. Kuznetsov ${ }^{\text {a }}$, G. Yakushcheva a , E. Savelyev ${ }^{\text {a }}$, V. Yapaskurt a, b, V. Shcherbakov ${ }^{\text {a, b }}$, A. Temiryasev a, \\ L. Zakharov ${ }^{\text {a }}$, V. Jitov ${ }^{\text {a }}$, D. Sudas ${ }^{\text {a, c }}$ \\ ${ }^{\text {a }}$ Rusijos mokslu akademijos Kotelnikovo radijo inžinerijos ir elektronikos institutas, Friazinas, Rusija \\ ${ }^{\mathrm{b}}$ Maskvos valstybinio universiteto Geologijos fakultetas, Maskva, Rusija

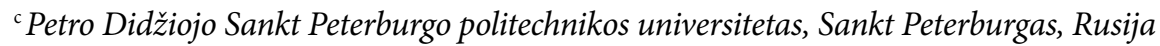

